\title{
$\mathrm{La}_{1.5} \mathrm{Sr}_{0.5} \mathrm{NiMn}_{0.5} \mathrm{Ru}_{0.5} \mathrm{O}_{6}$ Double Perovskite with Enhanced ORR/OER Bifunctional Catalytic Activity
}

Maria Retuerto $^{1 *}$, Federico Calle-Vallejo ${ }^{2}$, Laura Pascual ${ }^{3}$, Gunnar Lumbeeck ${ }^{4}$, María Teresa FernandezDiaz $^{5}$, Mark Croft ${ }^{6}$, Jagannatha Gopalakrishnan ${ }^{7}$, Miguel A. Peña ${ }^{1}$, Joke Hadermann ${ }^{4}$, Martha Greenblatt ${ }^{8}$, Sergio Rojas ${ }^{1 *}$

${ }^{1}$ Grupo de Energía y Química Sostenibles, Instituto de Catálisis y Petroleoquímica, CSIC. C/ Marie Curie 2, L10. 28049, Madrid, Spain.

2 Departament de Ciència de Materials i Química Fisica \& Institut de Química Teòrica i Computacional (IQTCUB), Universitat de Barcelona, Martí i Franqués 1, 08028 Barcelona, Spain

${ }^{3}$ Instituto de Catálisis y Petroleoquímica, CSIC. C/ Marie Curie 2, L10. 28049, Madrid, Spain.

${ }^{4}$ EMAT, University of Antwerp, Groenenborgerlaan 171, 2020 Antwerp, Belgium

5 Institut Laue-Langevin, BP156X, Grenoble, F-38042, France.

6 Department of Physics, Rutgers, The State University of New Jersey, 610 Taylor Road, Piscataway, New Jersey, 08854, USA

7 Solid State and Structural Chemistry Unit, Indian Institute of Science, Bangalore 560 012, India.

8 Department of Chemistry and Chemical Biology, Rutgers, The State University of New Jersey, 610

Taylor Road, Piscataway, New Jersey, 08854, USA

Corresponding Authors

* srojas@,icp.csic.es, m.retuerto@csic.es 
Table of Contents

S1. X-Ray Powder Diffraction

S2. Electron Diffraction

S3. Powder Neutron Diffraction

S4. X-ray absorption near edge spectroscopy (XANES)

S4.1. Ni-K and Mn-K pre-edges

S4.2. $4 d-L_{3}$ edges

S5. Electrochemical Performance

S5.1. Electrochemical impedance spectroscopy (EIS)

S5.2. $\mathrm{RRDE}$ measurement to determine the production of $\mathrm{H}_{2} \mathrm{O}_{2}$ during the ORR

\section{S5.3. ECSA}

S5.4. Intrinsic Activity

S5.5. ORR Kinetic current and Mass Activity

S5.6. $\mathrm{R} R D E$ measurement to determine the production of $\mathrm{O}_{2}$ during the OER

S6. BET Surface Area

S7. Computational Details

S8. Post Mortem TEM Study

S8.1. Postmortem ORR study

S8.2. Postmortem OER study

References 


\section{S1. X-Ray Powder Diffraction}

Figure $\mathrm{S} 1$ shows the Rietveld refinement of the structure of $\mathrm{La}_{1.5} \mathrm{Sr}_{0.5} \mathrm{NiMn}_{0.5} \mathrm{Ru}_{0.5} \mathrm{O}_{6}$ (LSNMR) in $\mathrm{P} 2 / n$ space group by $\mathrm{x}$-ray diffraction.

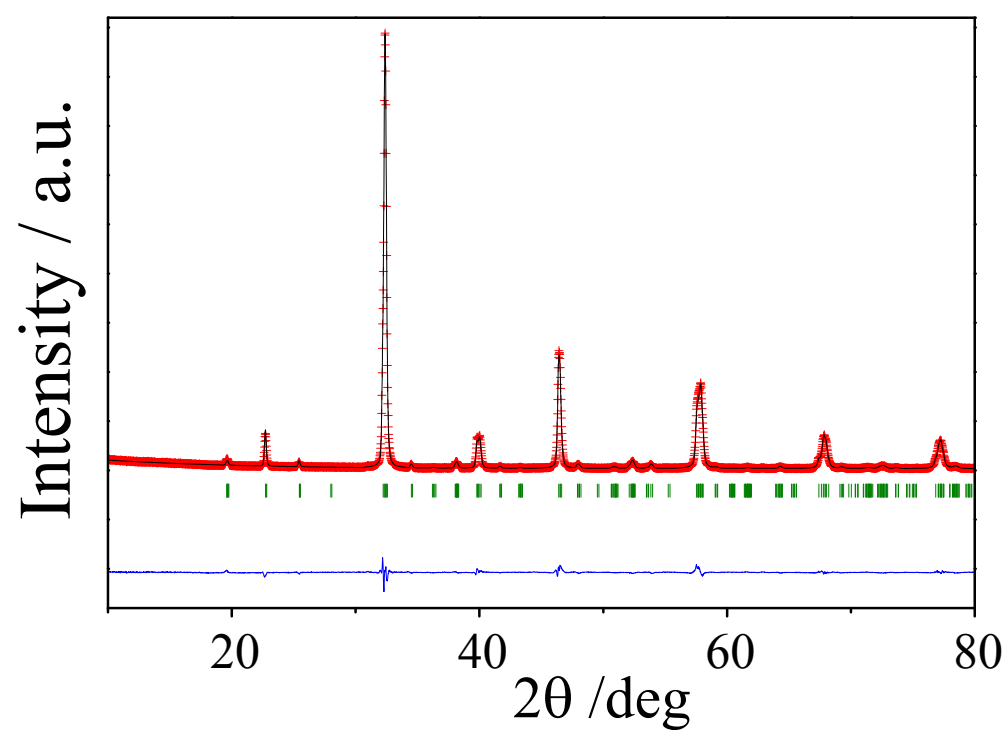

Figure S1. XRD Rietveld profiles of the structure of $\mathrm{La}_{1.5} \mathrm{Sr}_{0.5} \mathrm{NiMn}_{0.5} \mathrm{Ru}_{0.5} \mathrm{O}_{6}, \mathrm{LSNMR}$, refined with the $\mathrm{P} 2_{1} / n$ monoclinic space group. Crosses are the observed pattern, the black full line is the calculated one and the bottom blue line is the difference between both. The green lines indicate the Bragg reflections of the selected space group. 


\section{S2. Electron Diffraction}

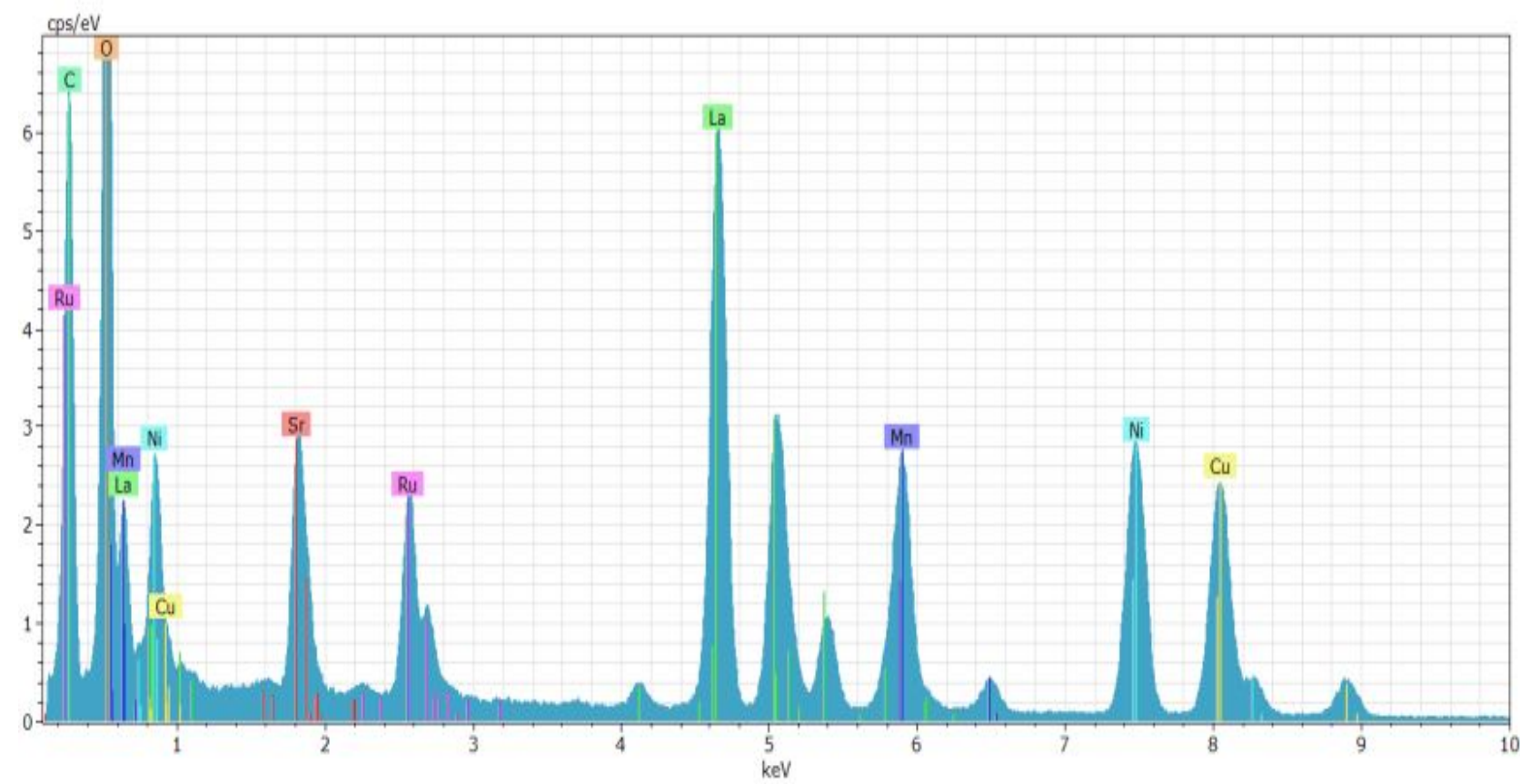

Figure S2. Representative EDX spectrum of LSNMR to illustrate the composition obtained.
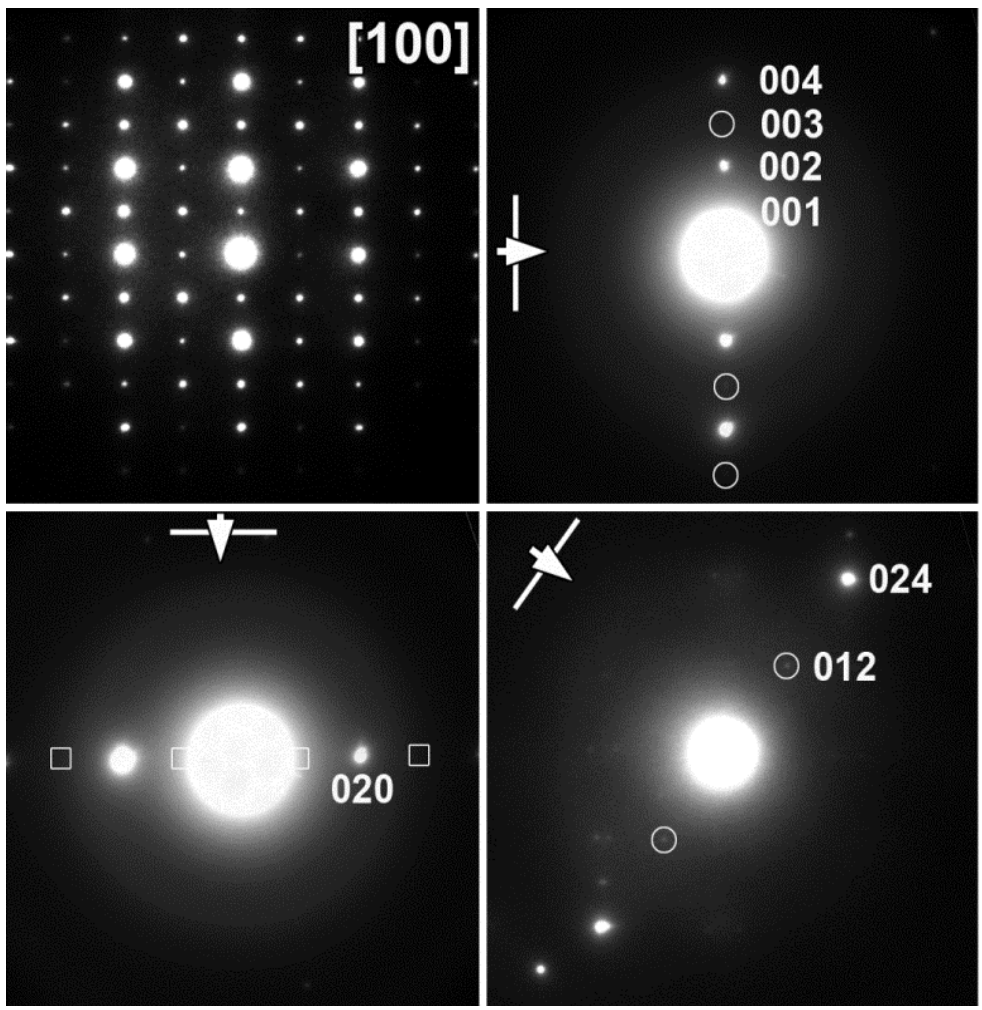

Figure S3. Selected Area Electron Diffraction (SAED) of LSNMR indexed in a perovskite cell. 
As shown in Figure S3, by tilting around the relevant rows of reflections, the 0k0: $\mathrm{k}=$ $2 \mathrm{n}+1$ reflections (indicated by squares) are due to double diffraction, since they disappear when removing the possible double diffraction paths, while 001: $1=2 \mathrm{n}+1$ (indicated by circles in the top right pattern) are not due to double diffraction. We investigated whether the [100] patterns could actually be twinned patterns of [100] with $0 \mathrm{kl}: \mathrm{k}=2 \mathrm{n}$ and [010] with $\mathrm{h} 0 \mathrm{l}: \mathrm{h}+\mathrm{l}=2 \mathrm{n}$, with the $0 \mathrm{kl}: \mathrm{k}=2 \mathrm{n}+1,1=2 \mathrm{n}$ being due to double diffraction only. This is necessary since this would exactly correspond to Pbnm (or in the conventional setting for perovskites Pnma with $\mathrm{a} \approx \sqrt{ } 2 \mathrm{a}_{\mathrm{p}}, \mathrm{b} \approx 2 \mathrm{a}_{\mathrm{p}}, \mathrm{c} \approx \sqrt{ } 2 \mathrm{a}_{\mathrm{p}}$ ), which has the same octahedral tilt pattern as $\mathrm{P} 2{ }_{1} / n$ but without cation order. The tilt around the $0 \mathrm{kl}: 1=2 \mathrm{k}$ row of reflections, shown also in Figure S3 (indicated by circles in the bottom right pattern), show that these reflections remain present even when all double diffraction paths to these reflections are eliminated. This proves that these reflections are not due to double diffraction on top of a twinned pattern, but that there is indeed no reflection condition for $0 \mathrm{kl}$ reflections. Therefore, only $\mathrm{P} 2_{1} / n$ is in agreement with the experimental electron diffraction results. 


\section{S3. Powder Neutron Diffraction}

Table S1. Atomic parameters after the refinement of the crystallographic structure of $\mathrm{La}_{1.5} \mathrm{Sr}_{0.5} \mathrm{NiMn}_{0.5} \mathrm{Ru}_{0.5} \mathrm{O}_{6}$ from high resolution PND data at $\mathrm{T}=295 \mathrm{~K}$. Space group $\mathrm{P} 2_{1} / n$. Lattice parameters: $\mathrm{a}=5.5458(3) \AA, \mathrm{b}=5.5035(3) \AA, \mathrm{c}=7.7985(4) \AA, \beta=89.95(1)^{\circ}$ and $\mathrm{V}=238.02(2) \AA^{3}$. Discrepancy factors: $\mathrm{R}_{\mathrm{p}}=2.38 \%, \mathrm{R}_{\exp }=2.17 \%, \mathrm{R}_{\mathrm{wp}}=3.07 \%$ and $\mathrm{R}_{\text {Bragg }}=5.57 \%, \chi^{2}=1.99$.

\begin{tabular}{ccccccc}
\hline Atom & Site & $\mathbf{x}$ & $\mathbf{y}$ & $\mathbf{z}$ & $\mathbf{f}_{\text {occ }}$ & $\mathbf{B}\left(\AA^{2}\right)$ \\
\hline $\mathrm{La} / \mathrm{Sr}$ & $4 e$ & $0.0032(8)$ & $0.0213(5)$ & $0.2518(9)$ & $0.75 / 0.25$ & $0.12(4)$ \\
$\mathrm{Ni} / \mathrm{Ru}$ & $2 a$ & $1 / 2$ & 0 & $1 / 2$ & $0.5 / 0.5$ & $0.17(5)$ \\
$\mathrm{Ni} / \mathrm{Mn}$ & $2 b$ & $1 / 2$ & 0 & 0 & $0.5 / 0.5$ & $0.17(5)$ \\
$\mathrm{O} 1$ & $4 e$ & $0.2937(9)$ & $0.2796(11)$ & $0.0322(9)$ & 1.000 & $0.01(4)$ \\
$\mathrm{O} 2$ & $4 e$ & $0.2429(9)$ & $0.7634(9)$ & $0.0320(8)$ & 1.000 & $0.01(4)$ \\
$\mathrm{O} 3$ & $4 e$ & $-0.0690(7)$ & $0.4909(8)$ & $0.26120(9)$ & 1.000 & $0.01(4)$ \\
\hline
\end{tabular}

Table S2. Atomic distances $(\AA)$ for $\mathrm{Ni} / \mathrm{RuO}_{6}$ and $\mathrm{Ni} / \mathrm{MnO}_{6}$ octahedra and selected bond angles $\left(^{\circ}\right)$ at 295 $\mathrm{K}$.

\begin{tabular}{ll}
\hline Description & Bond distance \\
\hline $\mathrm{Ni} / \mathrm{Ru}-\mathrm{O} 1(\mathrm{x} 2)$ & $2.046(5)$ \\
$\mathrm{Ni} / \mathrm{Ru}-\mathrm{O} 2(\mathrm{x} 2)$ & $1.995(5)$ \\
$\mathrm{Ni} / \mathrm{Ru}-\mathrm{O} 3(\mathrm{x} 2)$ & $2.073(6)$ \\
$<\mathrm{Ni} / \mathrm{Ru}-\mathrm{O}>$ & $2.038(2)$ \\
$\mathrm{Ni} / \mathrm{Mn}-\mathrm{O} 1(\mathrm{x} 2)$ & $1.934(6)$ \\
$\mathrm{Ni} / \mathrm{Mn}-\mathrm{O} 2(\mathrm{x} 2)$ & $1.947(5)$ \\
$\mathrm{Ni} / \mathrm{Mn}-\mathrm{O} 3(\mathrm{x} 2)$ & $1.902(6)$ \\
$<\mathrm{Ni} / \mathrm{Mn}-\mathrm{O}>$ & $1.928(2)$ \\
\hline $\mathrm{Description}$ & Angle \\
\hline$(\mathrm{Ru} / \mathrm{Ni}-\mathrm{O} 1-\mathrm{Mn} / \mathrm{Ni})$ & $157.9(2)$ \\
$(\mathrm{Ru} / \mathrm{Ni}-\mathrm{O} 2-\mathrm{Mn} / \mathrm{Ni})$ & $164.7(2)$ \\
$(\mathrm{Ru} / \mathrm{Ni}-\mathrm{O} 3-\mathrm{Mn} / \mathrm{Ni})$ & $157.6(3)$ \\
\hline
\end{tabular}




\section{S4. X-ray absorption near edge spectroscopy (XANES)}

\section{S4.1. Ni-K and Mn-K pre-edges}

The $3 \mathrm{~d}$ row transition metal pre-edge features are due to quadrupole-allowed transitions into final $d$-states or into hybridization-allowed dipole transitions into $d /$ ligand- $p$ states. Those are shifted below the main edge by the final state $d$-electron/core-hole Coulomb interaction. The spectral shape, intensity, and chemical shift of the pre-edge features can also be used as valence indicators. ${ }^{1-3}$ In the case of the Ni-K pre-edge, doping studies have shown a systematic increase in pre-edge feature intensity and chemical shift for $\mathrm{Ni}$ valences in the $2+$ to $3.3+$ range. ${ }^{1}$ In Figure S4a, the Ni-K pre-edge of LSNMR exhibits a low chemical shift and spectral area (close to $\mathrm{La}_{2} \mathrm{Ni}^{2+} \mathrm{VO}_{6}$ ). Thus, both the $\mathrm{Ni}-\mathrm{K}$ main edge and pre-edge results support $\mathrm{Ni}^{2+}$ configuration in LSNMR.
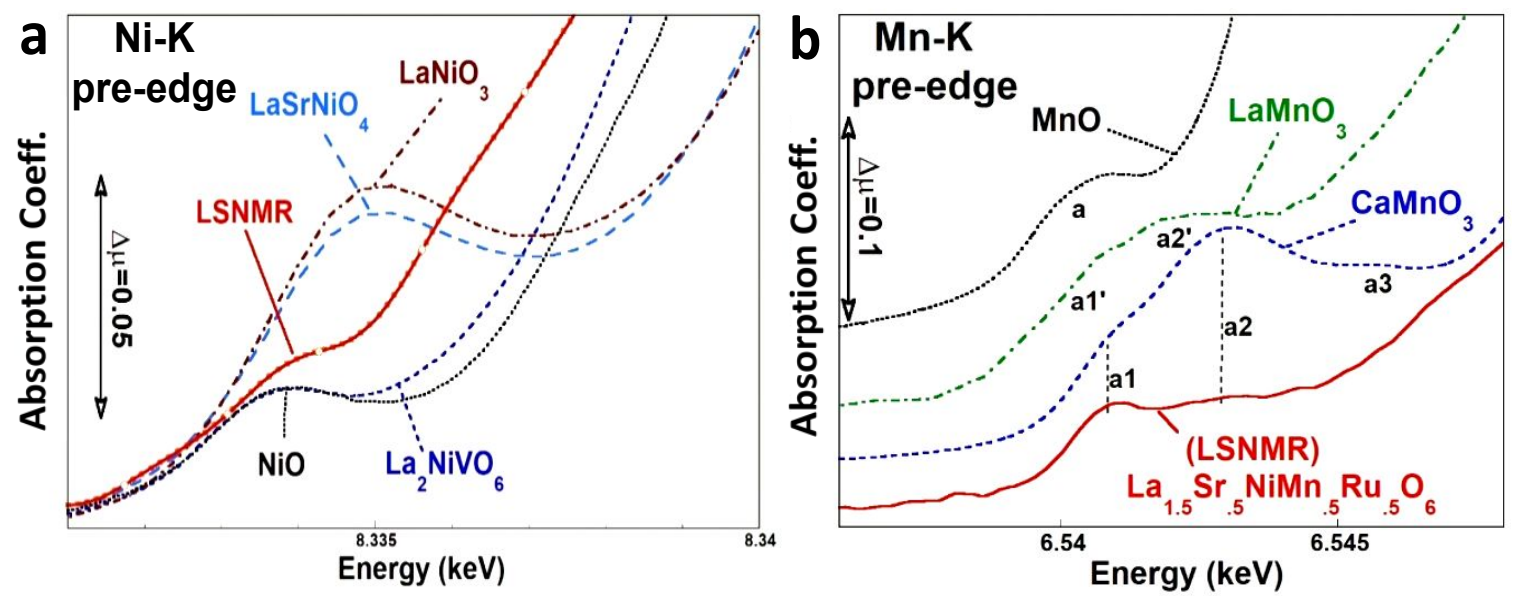

Figure S4(a). Ni-K pre-edge spectra for LSNMR and the standard compounds: $\sim \mathrm{Ni}^{2+}$ standards $\mathrm{NiO}$ and $\mathrm{La}_{2} \mathrm{NiVO}_{6}$; and $\sim \mathrm{Ni}^{3+}$ standards $\mathrm{LaNiO}_{3}$ and $\mathrm{LaSrNiO}_{4}$. (b) $\mathrm{Mn}-\mathrm{K}$ pre-edge spectra for LSNMR and the standard compounds: $\sim \mathrm{Mn}^{2+}, \mathrm{MnO} ; \sim \mathrm{Mn}^{3+}, \mathrm{LaMnO}_{3}$; and $\sim \mathrm{Mn}^{4+}, \mathrm{CaMnO}_{3}$. Note the standard spectra have been displaced vertically for clarity and nominal pre-edge features are identified.

Figure S4b compares the Mn-K pre-edge of LSNMR to those of standard Mn compounds. It should be noted that a1-a2 features for the $\mathrm{Mn}^{4+}$ standard are shifted up in energy relative to the a1'-a2' features in the $\mathrm{Mn}^{3+}$ standard. The a1-a2 features for LSNMR are similar in energy (albeit less intense) to the $\mathrm{Mn}^{4+}$ standard. Thus the $\mathrm{Mn}-\mathrm{K}$ pre-edge feature structure and intensity only supports a Mn valence well above 3+.

\section{S4.2. $4 d-L_{3}$ edges}

Figure S5 shows the systematic $\mathrm{M}(4 d)-\mathrm{L}_{3}$ edge variation with $4 d$-count for octahedral ligand coordination. The $\mathrm{L}_{2,3}$-edges of transition metals are dominated by intense "white line" (WL) spectral features at the edge onsets. ${ }^{3-6}$ These WL-features are due to transitions 
into empty $d$ final states and can be used as a probe of the $d$ occupancy through both their spectral distribution and chemical shift. In the case of $4 d$ transition metal compounds, with octahedral ligand coordination, the $4 d$-orbitals are split into a lower lying 6 -folddegenerate $t_{2 g}$ and excited 4-fold-degenerate $e_{g}$ states. To first-order this ligand field splitting is reflected in a splitting of the $4 \mathrm{~d}-\mathrm{L}_{2,3}$-edge WL-features in such compounds into a bimodal $\mathrm{A}\left(\mathrm{t}_{2 \mathrm{~g}}\right.$ related)/B( $\mathrm{e}_{\mathrm{g}}$ related) structure (see the $\mathrm{A}$ and $\mathrm{B}$ features and Figure $\mathrm{S} 5)$. This splitting is illustrated in Figure $\mathrm{S} 5$ for the $\mathrm{L}_{3}$ edges of $4 \mathrm{~d}$-row perovskite related compounds. ${ }^{3-6}$ It should be noted that the intensity of the $A\left(t_{2 g}\right.$ related $)$ feature systematically decreases, relative to the $\mathrm{B}\left(\mathrm{e}_{\mathrm{g}}\right.$ related $)$ feature, as the $4 \mathrm{~d}$ configuration increases from $4 d^{0}$ to $4 d^{4}$ (i.e. as the $t_{2 g}$ hole count decreases from 6 to 2). It is worth noting that while the ligand field split levels and systematic 4d-occupation trends are apparent in such compounds, multiplet and spin orbit interaction effects can also be discerned in 4d-row compounds. ${ }^{5}$

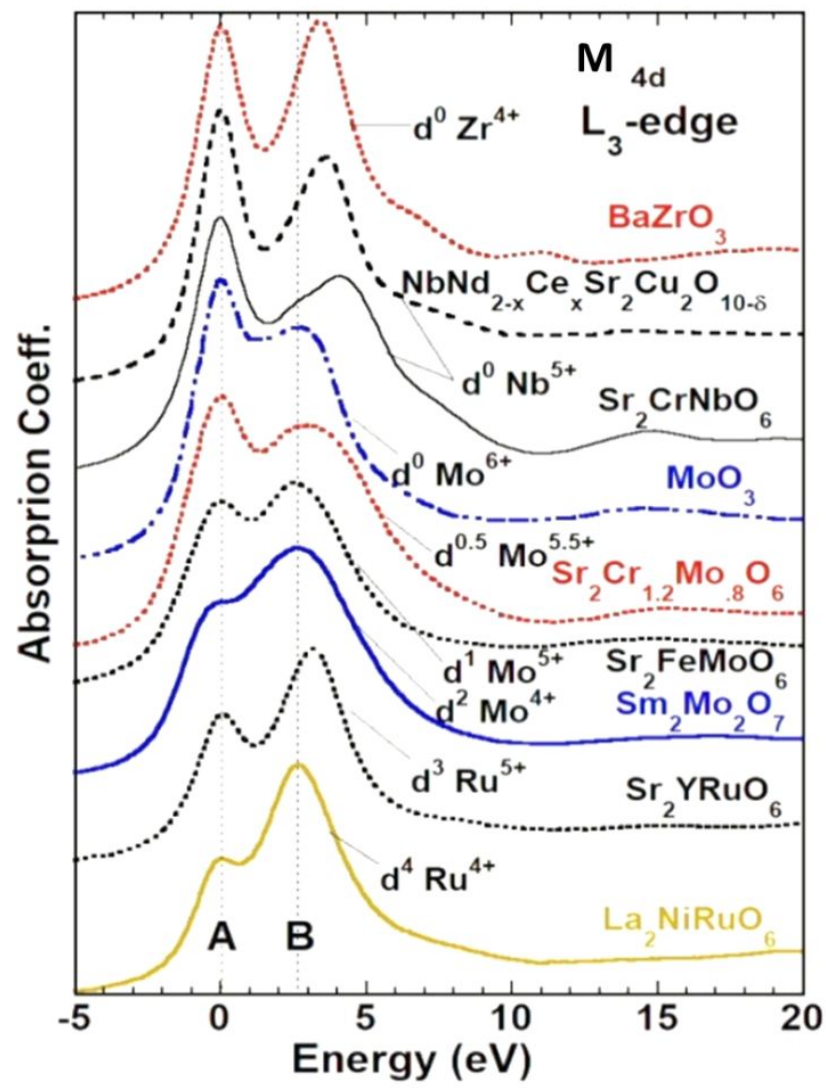

Figure S5. The $M-L_{3}$ edges of a series of $T_{4 d}$ compounds (with octahedral O-ligand symmetry), $T_{4 d}=Z r$, $\mathrm{Nb}$, Mo, and $\mathrm{Ru}$, with d-occupancies varying from $\mathrm{d}^{0}$ to $\mathrm{d}^{4}$. For comparison, the spectra have been nominally aligned to the A- $\left(\mathrm{t}_{2 \mathrm{~g}}\right.$ related $)$ feature. Note the systematic decrease in the A-feature intensity, relative to the $\mathrm{B}-\left(\mathrm{e}_{\mathrm{g}}\right.$ related) feature as the d-count increases (i.e. as the $\mathrm{d}$ final state hole count decreases). 
The first conclusion of the XANES is that it supports the LSNMR formula with the nominal formal valences of $\mathrm{Ni}^{2+}-\mathrm{Mn}^{4+}-\mathrm{Ru}^{5+}$, with the caveat that integral valence states in the solid-state environment are a substantial oversimplification. A configuration of the $\mathrm{Ni}^{2+}$ is strongly supported. A configuration of close to $\mathrm{Mn}^{4+}$ is evidenced with a quantitative estimate of $\mathrm{Mn}^{3.7+}$ being motivated by main-edge peak position. A configuration of close to $\mathrm{Ru}^{5+}$ is evidenced, but with the possibility of a somewhat smaller value based upon the chemical shift.

The main-edge evidence for the more precise estimate of $\mathrm{Mn}^{3.7+}$ does have an empirical basis and should be noted. In this regard it is worth noting that the weighted average of the SEM and TEM stoichiometries $\left[\mathrm{La}_{0.80(3)} \mathrm{Sr}_{0.24(3)} \mathrm{Ni}_{0.5(1)} \mathrm{Mn}_{0.27(3)} \mathrm{Ru}_{0.22(8)} \mathrm{O}_{\mathrm{x}}\right]$ would almost precisely agree with $\mathrm{Ni}^{2+}-\mathrm{Mn}^{3.7+}-\mathrm{Ru}^{5+}$ if $\mathrm{x}=3$. In view of the uncertainties, this stoichiometry/Mn-valence is likely fortuitous, but it emphasizes that the question of a possible Mn-valence somewhat lower than 4+ in LSNMR must remain open. The evidence for a Ru-valence slightly less than 5+ is less strong, but should also be considered an open question. 


\section{S5. Electrochemical Performance}

S5. 1. Electrochemical impedance spectroscopy (EIS)

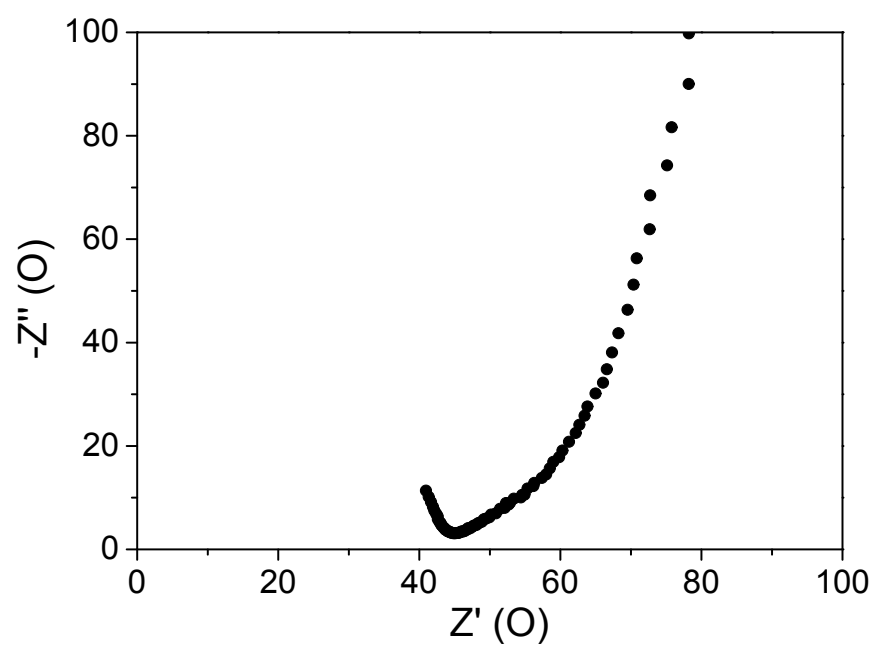

Figure S6. Nyquist plot of LSNMR from an electrochemical impedance spectroscopy experiment at open voltage.

S5.2. RRDE measurement to determine the production of $\mathrm{H}_{2} \mathrm{O}_{2}$ during the ORR.

The ORR can proceed via 4 electrons $\left(\mathrm{O}_{2} \rightarrow \mathrm{H}_{2} \mathrm{O}\right)$ or 2 electrons $\left(\mathrm{O}_{2} \rightarrow \mathrm{H}_{2} \mathrm{O}_{2}\right)$ and the relative production of $\mathrm{H}_{2} \mathrm{O}_{2}$ was assessed using a RRDE with a Pt ring at $1.2 \mathrm{~V}$ during the ORR reaction. At $1.2 \mathrm{~V}$, the $\mathrm{H}_{2} \mathrm{O}_{2}$ eventually formed during the $\mathrm{ORR}$, produces $\mathrm{O}_{2}$ at the Pt ring, giving oxidizing currents. The $\mathrm{H}_{2} \mathrm{O}_{2}$ fraction formed is calculated from the formula:

$\mathrm{X}_{\mathrm{H}_{2} \mathrm{O}_{2}}=\frac{\frac{{ }^{2 \mathrm{i}_{R}}}{\mathrm{~N}}}{\mathrm{i}_{\mathrm{D}}+\frac{\mathrm{i}_{\mathrm{R}}}{\mathrm{N}}}$

where $i_{D}$ is the current obtained at the disk and $i_{R}$ is the current obtained at the Pt ring. $N$ is the ring's efficiency, set at $26 \%$. The number of exchanged electrons is then calculated from:

ne $=4-\left(\frac{\mathrm{H}_{2} \mathrm{O}_{2}}{50 \%}\right)$

The RRDE measurement (Figure S7) shows that $6 \%$ of the product obtained during ORR is $\mathrm{H}_{2} \mathrm{O}_{2}$. 


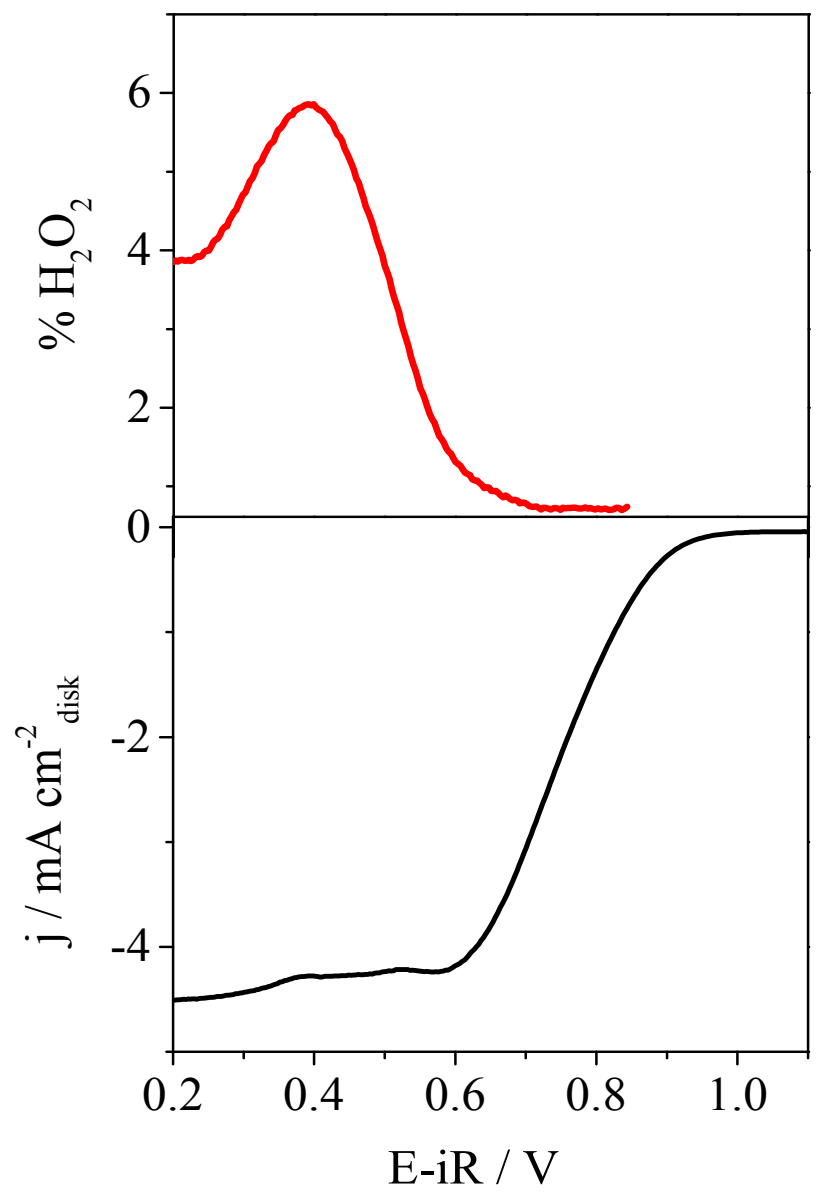

Figure S7. RRDE ORR measurement with the Pt ring settled at $1.2 \mathrm{~V}$.

\section{S5.3. ECSA}

The electrochemically active surface area (ECSA) was calculated by the double-layer capacitance of LSNMR without active carbon. We performed cyclic voltammograms at different velocities close to the "open circuit potential" in Ar, where it is suppose that the measured currents are due to double-layer charging. ECSA was recorded at 200, 100, 50, 20 and $10 \mathrm{mV} / \mathrm{s}$ between 0.78 and $0.98 \mathrm{~V} v s$. RHE (Figure S8). The double-layer charging current would be equal to the product of the scan rate $(v)$ and the double-layer capacitance $\left(\mathrm{C}_{\mathrm{dl}}\right)$ as $\mathrm{i}_{\mathrm{c}}=v_{\mathrm{dl}}$. If $\mathrm{i}_{\mathrm{c}}$ is plotted as a function of $v$, then the slope will be $\mathrm{C}_{\mathrm{dl}}$, and ECSA will be $\mathrm{ECSA}=\mathrm{C}_{\mathrm{dl}} / \mathrm{C}_{\mathrm{S}}$; where $\mathrm{C}_{\mathrm{S}}$ is the specific capacitance of an atomically flat planar surface of the material per unit area under identical electrolyte conditions. Since this value is not well established for oxides we used $0.06 \mathrm{mF} / \mathrm{cm}^{2}$, used in several references for $0.1 \mathrm{M} \mathrm{KOH} .^{7}$ The ECSA obtained was $2 \mathrm{~cm}^{2}$. 


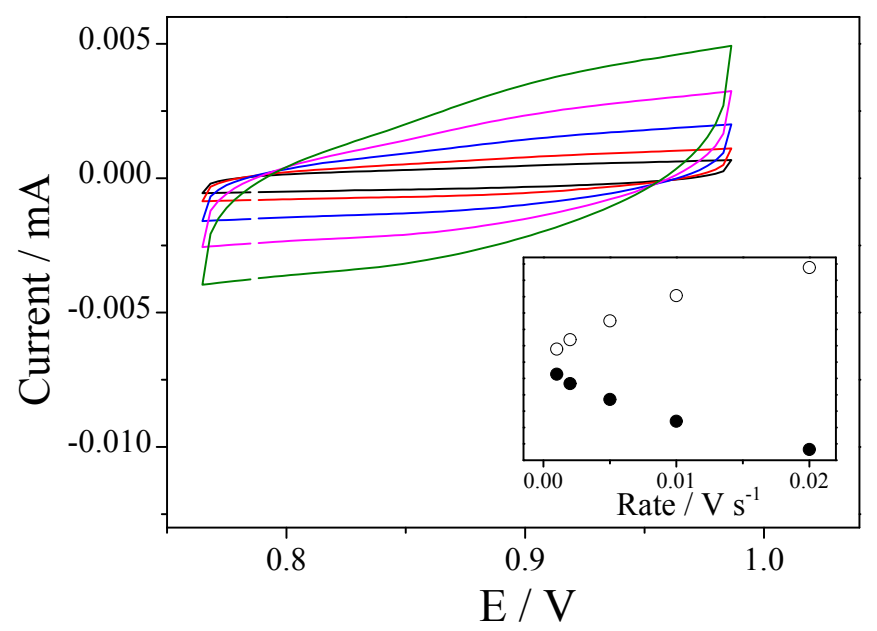

Figure S8. ECSA calculations of LSNMR.

\section{S5.4. Intrinsic Activity}

Intrinsic activities $\left(i_{s}\right.$ in $\mathrm{mAcm}^{-2}{ }_{\text {oxide }}$ ) were calculated by normalizing $i_{f}$ to the actual specific surface area of the oxide deposited on the electrode with the following equation:

$i_{S}=\frac{i_{f}}{\left(g_{\text {oxide }} B E T_{\text {oxide }}\right)}$

where $\mathrm{BET}_{\text {oxide }}$ is the specific surface area of LSNMR, namely $2 \mathrm{~m}^{2} / \mathrm{g}$, obtained from the BET measurements.

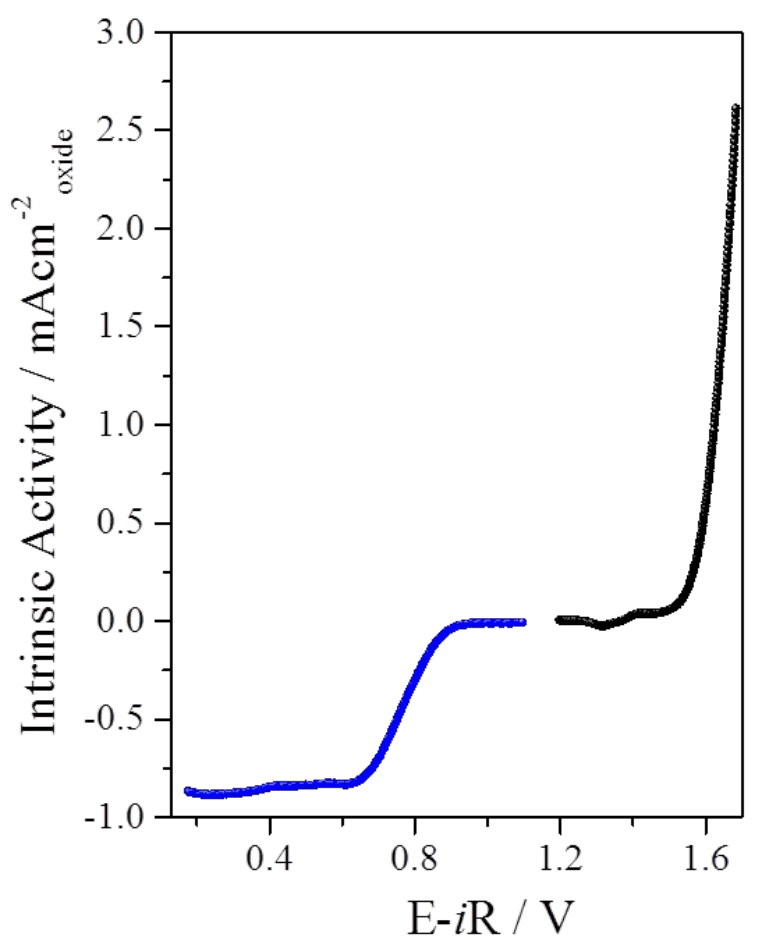

Figure S9. ORR and OER Intrinsic Activities of LSNMR.

S5.5. ORR Kinetic current and Mass Activity. 
ORR kinetic current $\left(i_{k}\right)$ are calculated from the Koutecky-Levich equation:

$i_{k}=-\frac{i_{F} \times i_{l i m}}{i_{F}-i_{l i m}}$

where $i_{F}$ is the Faradaic current and $i_{\text {lim }}$ is the limiting current. Using the kinetic current we calculate the mass activity of LSNMR (Figure $3 \mathrm{~b}$ of the main text):

$i_{m}=-\frac{i_{k}}{g_{\text {oxide }}}$

.6. $\mathrm{R} R D E$ measurement to determine the production of $\mathrm{O}_{2}$ during the OER.

We performed RRDE measurement during the OER in an electrolyte free of $\mathrm{O}_{2}$, with the $\mathrm{Pt}$ ring settled at $0.4 \mathrm{~V}$. At this potential the $\mathrm{O}_{2}$ produced during the OER reaction will be reduced on the Pt ring and give a reducing current (see Figure S10).

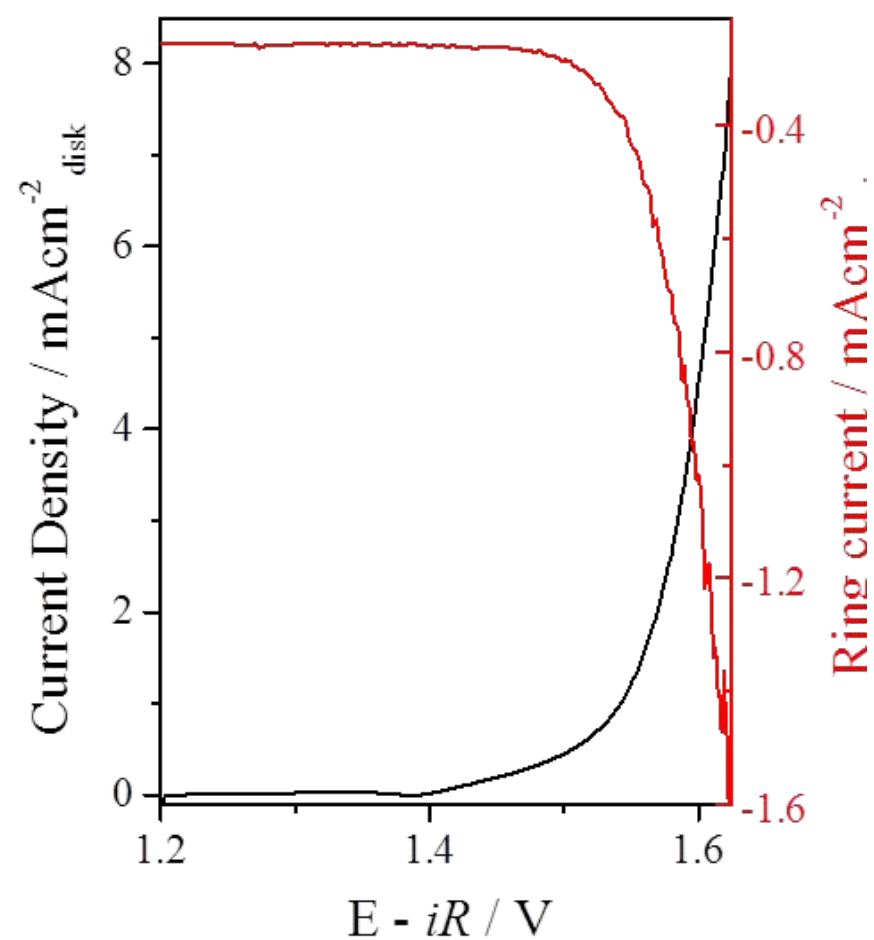

Figure S10. RRDE OER measurement with the Pt ring settled at $0.4 \mathrm{~V}$ to observe the reduction of the $\mathrm{O}_{2}$ formed during the OER reaction. 


\section{S6. BET Surface Area}

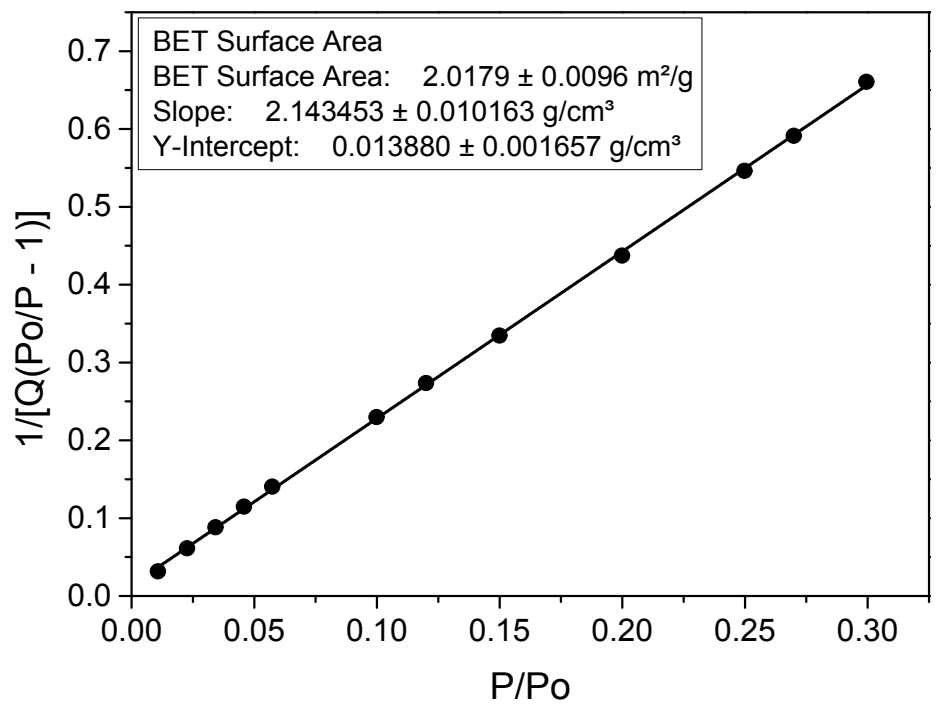

Figure S11: $\mathrm{La}_{1.5} \mathrm{Sr}_{0.5} \mathrm{NiMn}_{0.5} \mathrm{Ru}_{0.5} \mathrm{O}_{6} \mathrm{BET}$ surface area plot.

\section{S7. Computational Details}

We performed the DFT calculations with VASP ${ }^{8}$ with the projector augmented wave (PAW) approach, ${ }^{9}$ the GGA-PBE exchange-correlation functional, ${ }^{10}$ and Dudarev's $\mathrm{DFT}+\mathrm{U}$ formalism ${ }^{11}$ with $U_{\text {eff }}$ values of $6.01 \mathrm{eV}$ for $\mathrm{Ni}, 4.46$ for $\mathrm{Mn}$, and 6.70 for $\mathrm{Ru}$ ions. For $\mathrm{Ni}$ and $\mathrm{Mn}$ the values used are the average of those reported by Ceder and coworkers $^{12}$ for various $\mathrm{Ni}$ - and $\mathrm{Mn}$-containing compounds. For $\mathrm{Ru}$ we used the value reported by $\mathrm{Xu}$ et al. ${ }^{13}$

We used $2 \times 2(001)$ perovskite slabs to simulate the surfaces ( 4 atomic layers thick: atoms in the topmost two layers and the adsorbates were fully relaxed, whereas the bottommost two were fixed at the equilibrium bulk distances, please refer to Figure S12), which contained four formula units in each case, with $4 \times 4 \times 1 \mathrm{k}$-point grids and a plane-wave cutoff of $450 \mathrm{eV}$. We added $\sim 15 \AA$ of vacuum in the $\mathrm{z}$ direction to avoid interactions between periodically repeated slabs. As shown in previous works, this setup suffices for the adsorption energies to be converged within $0.05 \mathrm{eV} \cdot{ }^{14-16}$ 


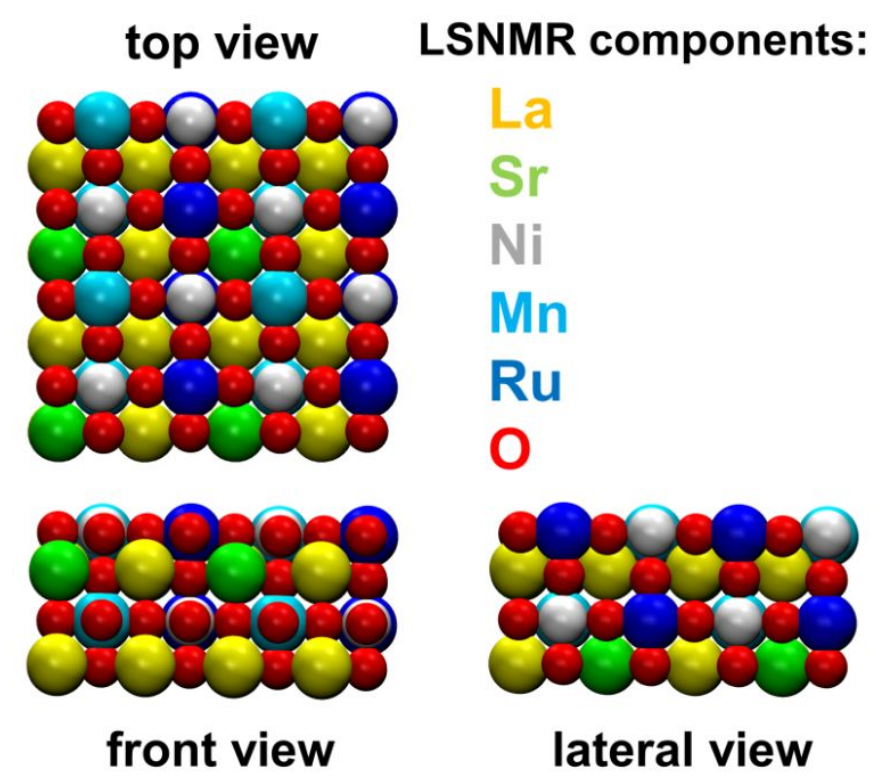

Figure S12. Top, front and side views of the LSNMR slabs under study. The colour code for each component is provided in the figure.

The calculations were made spin unrestricted in all cases. The relaxations were made with the conjugate-gradient scheme with $k_{B} T=0.01 \mathrm{eV}$ and Gaussian smearing, taking the energies extrapolated to $0 \mathrm{~K}$, until the maximal force on the relaxed atoms was $0.05 \mathrm{eV} / \AA$. $\mathrm{H}_{2} \mathrm{O}$ and $\mathrm{H}_{2}$ were calculated in boxes of $15 \AA \times 15 \AA \times 15 \AA$ and a $1 \times 1 \times 1$ k-point grid with $k_{B} T=0.001 \mathrm{eV}$. The Gibbs energies were approximated as: $G \approx E_{D F T}+Z P E-T S$, where $E_{D F T}$ and $Z P E$ are the DFT-calculated total and zero-point energies respectively, while $T S$ are entropic corrections for fluid-phase species. For $\mathrm{H}_{2} \mathrm{O}(1)$ and $\mathrm{H}_{2}(\mathrm{~g})$ the $T S$ corrections are 0.67 and 0.40 at $298.15 \mathrm{~K},{ }^{17}$ while the ZPEs for $\mathrm{H}_{2} \mathrm{O}$ and $\mathrm{H}_{2}$ are 0.58 and $0.28 \mathrm{eV} .{ }^{17}$ The ZPEs for ${ }^{*} \mathrm{O},{ }^{*} \mathrm{OH}$ and ${ }^{*} \mathrm{OOH}$ are $0.07,036$ and $0.43 \mathrm{eV}$.

To describe the energetics of $\left(\mathrm{H}^{+}+\mathrm{e}^{-}\right)$in terms of $1 / 2 \mathrm{H}_{2}(\mathrm{~g})$ we used the computational hydrogen electrode. ${ }^{18}$ Details on the construction of scaling-relation-based volcano plots appear elsewhere. ${ }^{19}$ We assume that the OER mechanism is $\mathrm{OH}^{-} \rightarrow{ }^{*} \mathrm{OH} \rightarrow{ }^{*} \mathrm{O} \rightarrow{ }^{*} \mathrm{OOH} \rightarrow \mathrm{O}_{2}$. The OER overpotential is calculated as:

$\eta_{O E R}=\max \left(\Delta G_{1}, \Delta G_{2}, \Delta G_{3}, \Delta G_{4}\right) / e-E^{0}$

where $\Delta G_{1}=\Delta G_{O H}, \Delta G_{2}=\Delta G_{O}-\Delta G_{O H}, \Delta G_{3}=\Delta G_{O O H}-\Delta G_{O}, \Delta G_{4}=4 E^{0}-\Delta G_{O O H}$, and $E^{0}=1.23 \mathrm{~V}$ is the equilibrium potential of the reaction. Note that $\Delta \mathrm{G}_{\mathrm{O}}$ is the reaction energy of $*+\mathrm{H}_{2} \mathrm{O} \rightarrow * \mathrm{O}+2 \mathrm{H}^{+}+2 e^{-}, \quad \Delta \mathrm{G}_{\mathrm{OH}}$ is the reaction energy of $*+\mathrm{H}_{2} \mathrm{O} \rightarrow * \mathrm{OH}+\mathrm{H}^{+}+e^{-}$, and $\Delta \mathrm{G}_{\mathrm{OOH}}$ is in turn the reaction energy of 
${ }^{*}+2 \mathrm{H}_{2} \mathrm{O} \rightarrow * \mathrm{OOH}+3 \mathrm{H}^{+}+3 e^{-}$. From the acid-based reference of the adsorption energies to the alkaline one is based on the reaction $\mathrm{H}_{2} \mathrm{O} \rightarrow \mathrm{H}^{+}+\mathrm{OH}^{-}$, which has a free energy of $0.83 \mathrm{eV}$. Note that the use of either scale has no influence on the predicted overpotentials. The electrochemical-step symmetry index (ESSI) is defined as follows for the OER: ${ }^{20}$

$$
E S S I=\left(\frac{1}{n} \sum_{i}^{n} \Delta G_{i}^{*}\right)-E^{0}
$$

where $\Delta G_{i}^{*}$ are the adsorption energies in $\Delta G_{1}$ to $\Delta G_{4}$ larger than $E^{0}=1.23 \mathrm{~V}$. For instance, the adsorption energies of $* \mathrm{O}, * \mathrm{OH}$, and *OOH for Ru sites at LSNMR $(\mathrm{Ru} @$ LSNMR) are 2.27, 0.54, and $3.89 \mathrm{eV}$, according to Table S3. 0.54, $1.73,1.62$ and $1.03 \mathrm{eV}$, so that the overpotential is $\eta_{O E R}^{L S N M R}=1.73-1.23=0.50 \mathrm{~V}$ and $\operatorname{ESSI}_{\text {OER }}^{\text {LSNMR }}=(1.73+1.62) / 2-1.23=0.44 \mathrm{~V}$.

If the ORR is assumed to proceed as: $\mathrm{O}_{2} \rightarrow{ }^{*} \mathrm{OOH} \rightarrow{ }^{*} \mathrm{O} \rightarrow{ }^{*} \mathrm{OH} \rightarrow \mathrm{OH}^{-}$, one can make an analogous analysis so as to be able to calculate $\eta_{\mathrm{ORR}}, \mathrm{ESSI}_{\mathrm{ORR}}{ }^{20}$ and the bifunctional index as:

$$
B I=\eta_{O E R}+\eta_{O R R}
$$

Table $\mathrm{S} 3$ contains $\Delta \mathrm{G}_{\mathrm{O}}, \Delta \mathrm{G}_{\mathrm{OH}}, \Delta \mathrm{G}_{\mathrm{OOH}}, \mathrm{ESSI}_{\mathrm{OER}}, \mathrm{ESSI}_{\mathrm{ORR}}, \eta_{\mathrm{OER}}$ and $\eta_{\mathrm{ORR}}$ for the different sites on LSNMR.

Table S3. Adsorption energies $(\mathrm{eV})$ of $* \mathrm{O},{ }^{*} \mathrm{OH}$ and $* \mathrm{OOH}$ on the different sites of LSNMR, ESSI values (V) and calculated overpotentials (V) for the OER and the ORR. The values in bold are used to determine the BI of LSNMR.

\begin{tabular}{lccccccc}
\hline description & $\Delta \mathrm{G}_{\mathrm{O}}$ & $\Delta \mathrm{G}_{\mathrm{OH}}$ & $\Delta \mathrm{G}_{\mathrm{OOH}}$ & ESSI $_{\mathrm{OER}}$ & $\eta_{\mathrm{OER}}$ & ESSI $_{\mathrm{ORR}}$ & $\eta_{\mathrm{ORR}}$ \\
\hline Ni@LSNMR & 3.71 & 1.47 & 4.41 & 0.62 & 1.01 & -0.62 & 0.72 \\
$\mathrm{Mn} @$ LSNMR & 3.12 & 0.96 & 4.08 & 0.93 & 0.93 & $\mathbf{- 0 . 3 1}$ & $\mathbf{0 . 3 9}$ \\
$\mathrm{Ru} @$ LSNMR & 2.27 & 0.54 & 3.89 & $\mathbf{0 . 4 4}$ & $\mathbf{0 . 5 0}$ & -0.44 & 0.69 \\
\hline
\end{tabular}

In Figure S13 we provide the correlation between $\triangle E S S I=E S S I_{O E R}-E S S I_{O R R}$ and BI for $\mathrm{Ru}, \mathrm{Ni}$ and Mn sites at LSNMR, the best combination of those made from Mn sites for the ORR and Ru sites for the OER, and additional data from the literature for other oxides: $\mathrm{RuO}_{2},{ }^{16} \mathrm{IrO}_{2},{ }^{16} \mathrm{MnO}_{\mathrm{x}},{ }^{16} \mathrm{Co}_{\mathrm{x}} \mathrm{O}_{\mathrm{y}},{ }^{16,21}$ and $\mathrm{Pt}(111) / \mathrm{PtO}_{2} \cdot{ }^{16,22}$ For $\mathrm{Pt}(111)$ we extrapolated the data in ref..$^{22}$ from the fully solvated environment to the onset potential conditions where high adsorbate coverages are expected to weaken the adsorption energies of ${ }^{*} \mathrm{O}$, $* \mathrm{OH}$ and ${ }^{*} \mathrm{OOH}$ at least by $\sim 0.4,0.19$ and $0.17 \mathrm{eV}$. Following the surface Pourbaix 
diagrams, for $\mathrm{Co}_{\mathrm{x}} \mathrm{O}_{\mathrm{y}}$ we used the OER data for $\mathrm{CoOOH}$ and the ORR data for $\mathrm{Co}_{3} \mathrm{O}_{4}$. Likewise, for $\mathrm{MnO}_{\mathrm{x}}$ we used the OER data for $\mathrm{MnO}_{2}$ and the ORR data for $\mathrm{Mn}_{2} \mathrm{O}_{3}$. The mean absolute error (MAE) between the linear fit and the data is only $0.10 \mathrm{~V}$. The experimental data in the inset of Figure 4 in the main text was taken from this study for LSNMR and from various references for the other materials $\left(\mathrm{RuO}_{2},{ }^{23-24} \mathrm{MnO}_{\mathrm{x}}{ }^{24} \mathrm{Pt} / \mathrm{C},{ }^{25}\right.$ $\left.\mathrm{IrO}_{2},{ }^{25} \mathrm{Co}_{\mathrm{y}} \mathrm{O}_{\mathrm{x}}{ }^{23}\right)$.

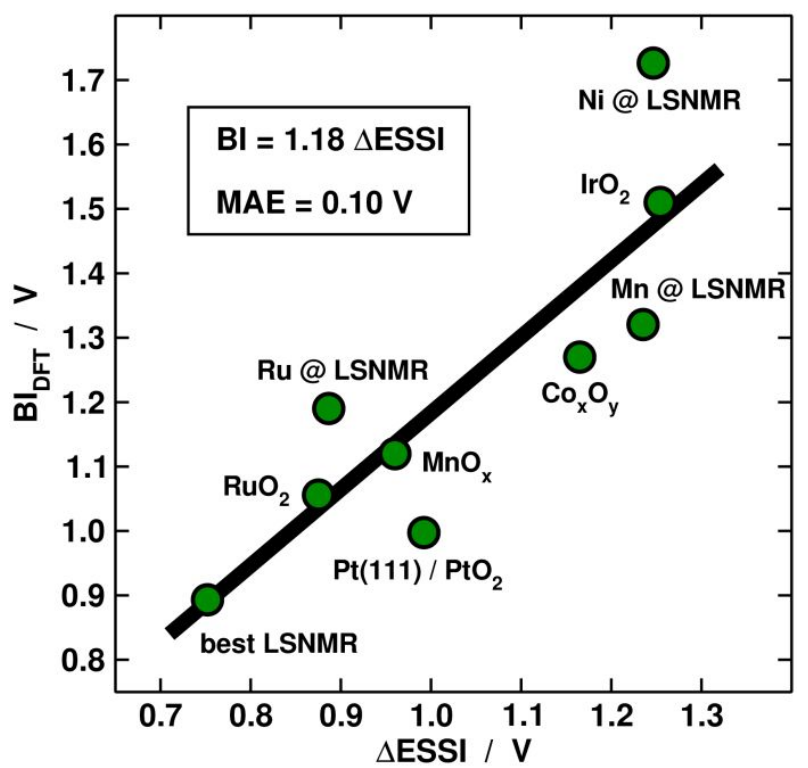

Figure S13. Correlation between $\triangle \mathrm{ESSI}$ and the DFT-calculated BI for several electrocatalysts in this study and the literature (see this SI for the data sources). 


\section{S8. Post Mortem TEM Study}

\section{S8.1. Postmortem ORR study}
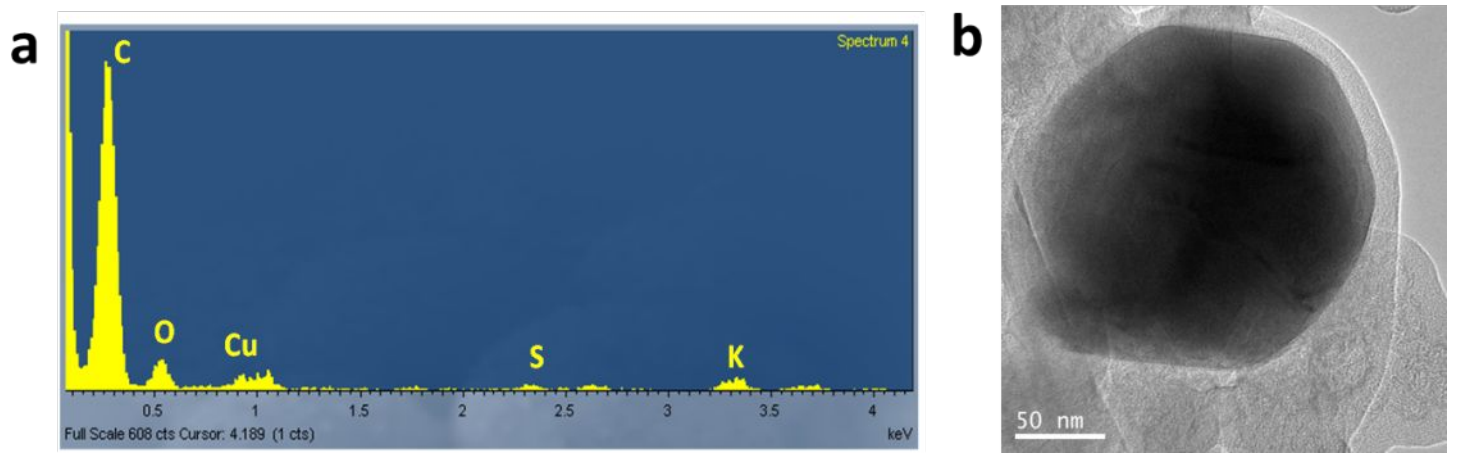

Figure S14. a) EDX of the amorphous regions around the perovskite particles. b) TEM of a particle covered by carbon.

\section{S8.2. Postmortem OER study}

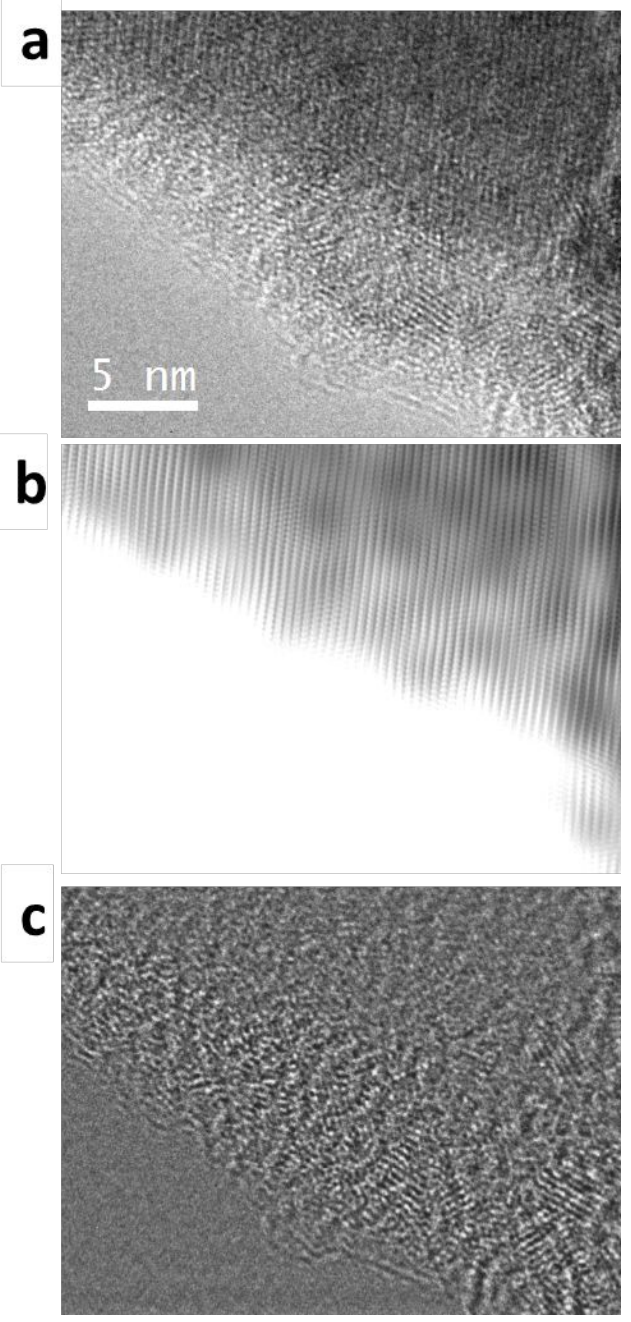

Figure S15. a) HR-TEM image of an isolated degraded particle after 500 OER cycles. b) FFT filtered image of the HR-TEM using only the reflections corresponding to the perovskite, showing that the periodicity of the structure is maintained in the bulk, and c) filtered image of the HR-TEM with the rest of reflections, indicating the presences of nanoparticles and high disorder mainly at 5-10 $\mathrm{nm}$ in the surface. 


\section{References}

1. Sahiner, A.; Croft, M.; Guha, S.; Perez, I. I.; Zhang, Z.; Greenblatt, M.; Metcalf, P. A.; Jahns, H.; Liang, G., Polarized Xas Studies of Ternary Nickel Oxides. Phys Rev B Condens Matter. 1995, 51 (9), 5879-5886.

2. Mandal, T. K.; Croft, M.; Hadermann, J.; Van Tendeloo, G.; Stephens, P. W.; Greenblatt, M., $\mathrm{La}_{2} \mathrm{MnVO}_{6}$ Double Perovskite: a Structural, Magnetic and X-ray Absorption Investigation. Journal of Materials Chemistry 2009, 19 (25), 4382.

3. Bune, R. O.; Lobanov, M. V.; Popov, G.; Greenblatt, M.; Botez, C. E.; Stephens, P. W.; Croft, M.; Hadermann, J.; Tendeloo, G. V., Crystal Structure and Properties of Ru-Stoichiometric $\mathrm{LaSrMnRuO}_{6}$. Chem. Mater. 2006, 18, 2611-2617.

4. Retuerto, M.; Li, M.-R.; Go, Y.; Ignatov, A.; Croft, M.; Ramanujachary, K.; Hadermann, J.; Hodges, J.; Herber, R.; Nowik, I., Magnetic and Structural Studies of the Multifunctional Material $\mathrm{SrFe}_{0.75} \mathrm{Mo}_{0.25} \mathrm{O}_{3-\delta}$. Inorganic chemistry 2012, 51 (22), 12273-12280.

5. $\quad$ Groot, F. M. F. d.; Z. W. Hu; Lopez, M. F.; Kaindl, G.; Guillot, F.; Tronc, M., Differences Between $\mathrm{L}_{3}$ and $\mathrm{L}_{2} \mathrm{X}$-Ray Absorption Spectra of Transition Metal Compounds. J. Chem. Phys. 1994, $101(8), 6570-6576$.

6. Hu, Z.; Lips, H. v.; Golden, M. S.; Fink, J.; Kaindl, G.; Groot, F. M. F. d.; Ebbinghaus, S.; Reller, A., Multiplet Effects in the Ru- $\mathrm{L}_{2,3} \mathrm{X}$-Ray Absorption Spectra of $\mathrm{Ru}(\mathrm{IV})$ and $\mathrm{Ru}(\mathrm{V})$ Compounds. Physical Review B 2000, 61 (8), 5262.

7. McCrory, C. C.; Jung, S.; Peters, J. C.; Jaramillo, T. F., Benchmarking Heterogeneous Electrocatalysts for the Oxygen Evolution Reaction. J Am Chem Soc 2013, 135 (45), 16977-87.

8. Kresse, G.; Furthmüller, J., Efficient Iterative Schemes for Ab Initio Total-Energy Calculations Using a Plane-Wave Basis Set. Physical Review B 1996, 54 (16), 11169-11186.

9. Kresse, G.; Joubert, D., From Ultrasoft Pseudopotentials to the Projector AugmentedWave Method. Physical Review B 1999, 59 (3), 1758-1775.

10. Perdew, J. P.; Burke, K.; Ernzerhof, M., Generalized Gradient Approximation Made Simple. Physical Review Letters 1996, 77 (18), 3865-3868.

11. Dudarev, S. L.; Botton, G. A.; Savrasov, S. Y.; Humphreys, C. J.; Sutton, A. P., ElectronEnergy-Loss Spectra and the Structural Stability of Nickel Oxide: An LSDA+U study. Physical Review B 1998, 57 (3), 1505-1509.

12. Zhou, F.; Cococcioni, M.; Marianetti, C. A.; Morgan, D.; Ceder, G., First-Principles Prediction of Redox Potentials in Transition-Metal Compounds With LDA+U. Physical Review B 2004, 70 (23), 235121.

13. Xu, Z.; Rossmeisl, J.; Kitchin, J. R., A Linear Response DFT+U Study of Trends in the Oxygen Evolution Activity of Transition Metal Rutile Dioxides. J. Phys. Chem. C 2015, 119 (9), 4827-4833.

14. Calle-Vallejo, F.; Inoglu, N. G.; Su, H.-Y.; Martínez, J. I.; Man, I. C.; Koper, M. T. M.; Kitchin, J. R.; Rossmeisl, J., Number of Outer Electrons as Descriptor for Adsorption Processes on Transition Metals and Their Oxides. Chemical Science 2013, 4 (3), 1245.

15. Calle-Vallejo, F.; Díaz-Morales, O. A.; Kolb, M. J.; Koper, M. T. M., Why Is Bulk Thermochemistry a Good Descriptor for the Electrocatalytic Activity of Transition Metal Oxides? ACS Catal. 2015, 5 (2), 869-873.

16. Man, I. C.; Su, H.-Y.; Calle-Vallejo, F.; Hansen, H. A.; Martinez, J. I.; Inoglu, N. G.; Kitchin, J.; Jaramillo, T. F.; Norskov, J. K.; Rossmeisl, J., Universality in Oxygen Evolution Electrocatalysis on Oxide Surfaces. ChemCatChem 2011, 3 (7), 1159-1165.

17. Briquet, L. G. V.; Sarwar, M.; Mugo, J.; Jones, G.; Calle-Vallejo, F., A New Type of Scaling Relations to Assess the Accuracy of Computational Predictions of Catalytic Activities Applied to the Oxygen Evolution Reaction. ChemCatChem 2017, 9 (7), 1261-1268.

18. Nørskov, J. K.; Rossmeisl, J.; Logadottir, A.; Lindqvist, L.; Kitchin, J. R.; Bligaard, T.; Jónsson, H., Origin of the Overpotential for Oxygen Reduction at a Fuel-Cell Cathode. J. Phys. Chem. B 2004, 108 (46), 17886-17892.

19. Calle-Vallejo, F.; Koper, M. T. M., First-Principles Computational Electrochemistry: Achievements and Challenges. Electrochimica Acta 2012, 84, 3-11. 
20. Govindarajan, N.; García-Lastra, J. M.; Meijer, E. J.; Calle-Vallejo, F., Does the Breaking of Adsorption-Energy Scaling Relations Guarantee Enhanced Electrocatalysis? Current Opinion in Electrochemistry 2018, 8, 110-117.

21. Bajdich, M.; García-Mota, M.; Vojvodic, A.; Nørskov, J. K.; Bell, A. T., Theoretical Investigation of the Activity of Cobalt Oxides for the Electrochemical Oxidation of Water. J. Am. Chem. Soc. 2013, 135 (36), 13521-13530.

22. Calle-Vallejo, F.; Tymoczko, J.; Colic, V.; Vu, Q. H.; Pohl, M. D.; Morgenstern, K.; Loffreda, D.; Sautet, P.; Schuhmann, W.; Bandarenka, A. S., Finding Optimal Surface Sites on Heterogeneous Catalysts by Counting Nearest Neighbors. Science 2015, 350 (6257), 185.

23. Masa, J.; Xia, W.; Sinev, I.; Zhao, A.; Sun, Z.; Grützke, S.; Weide, P.; Muhler, M.; Schuhmann, W., $\mathrm{Mn}_{\mathrm{x}} \mathrm{O}_{\mathrm{y}} / \mathrm{NC}$ and $\mathrm{Co}_{\mathrm{x}} \mathrm{O}_{\mathrm{y}} / \mathrm{NC}$ Nanoparticles Embedded in a Nitrogen-Doped Carbon Matrix for High-Performance Bifunctional Oxygen Electrodes. Angewandte Chemie International Edition 2014, 53 (32), 8508-8512.

24. Su, H.-Y.; Gorlin, Y.; Man, I. C.; Calle-Vallejo, F.; Nørskov, J. K.; Jaramillo, T. F.; Rossmeisl, J., Identifying Active Surface Phases for Metal Oxide Electrocatalysts: a Study of Manganese Oxide Bi-Functional Catalysts for Oxygen Reduction and Water Oxidation Catalysis. Phys. Chem. Chem. Phys. 2012, 14 (40), 14010-14022.

25. Aijaz, A.; Masa, J.; Rösler, C.; Xia, W.; Weide, P.; Botz, A. J. R.; Fischer, R. A.; Schuhmann, W.; Muhler, M., Co@ $\mathrm{Co}_{3} \mathrm{O}_{4}$ Encapsulated in Carbon Nanotube-Grafted NitrogenDoped Carbon Polyhedra as an Advanced Bifunctional Oxygen Electrode. Angewandte Chemie International Edition 2016, 55 (12), 4087-4091. 